\title{
EDITORIAL
}

\section{The second year of the Journal of Hematopathology has started}

\author{
J. H. van Krieken
}

Published online: 7 March 2009

(C) Springer-Verlag 2009

The second year of the Journal of Hematopathology has started with this first and rich issue. The previous issue that was the first one printed, at the occasion of the Bordeaux Meeting of the EAHP and the SH, was very well received and contained the abstracts for the lymphoma and bone marrow symposium. That these two fields are really the pillars of Hematopathology is reflected by the two reviews that are in this issue, one on lymphomas and one on bone marrow. The first one is already number 3 in a hopefully long series, the latter one is by Jon vanderWalt, and is the first. Therefore, this covers a real helicopter view of the developments of 2008 .
One of the most important developments in 2008 was clearly the presentation of the updated WHO classification. There are substantial changes compared to the previous version and the editorial team of the Journal of Hematopathology has decided to write a series of commentaries on the important changes. These commentaries will be bundled in the next issue, but will be released previously on the website of the Journal!

I hope you will enjoy this issue and I am always open for comments and ideas and obviously for good new papers.

Han van Krieken

J. H. van Krieken $(\bowtie)$

Department of Pathology,

Radboud University Nijmegen Medical Centre,

P.O. Box 9101, 6500 HB Nijmegen, The Netherlands

e-mail: j.vankrieken@pathol.umcn.nl 